\title{
Silica Chloride Nano Particle Catalyzed Synthesis of 2,2'-(arylmethylene)bis(5,5-dimethylcyclohexane-1,3-dione) Derivatives
}

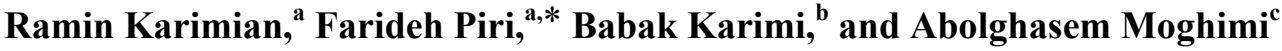 \\ ${ }^{a}$ Department of Chemistry, Faculty of Science, Zanjan University, P.O. Box 45195-313 Zanjan, I.R. Iran \\ ${ }^{\mathrm{b}}$ Department of Chemistry, Institute for Advanced Studies in Basic Sciences (IASBS), P.O. Box 45195-1159, \\ Gava Zang, Zanjan, Iran \\ ${ }^{\mathrm{c}}$ Department of Chemistry, Imam Hossein University, P.O. Box 16575-347, Tehran, Iran
}

Abstract. Silica chloride nano particle (nano $\mathrm{SiO}_{2}-\mathrm{Cl}$ ), has been found to be heterogeneous catalyst for facile and simple condensation of dimedone with aromatic aldehydes into 2,2'-(arylmethylene)bis(5,5dimethylcyclohexane-1,3-dione) derivatives in dry $\mathrm{CH}_{2} \mathrm{Cl}_{2}$. (doi: 10.5562/cca1721)

Keywords: dimedone; Knoevenagel condensation, Michael addition; 2,2-(arylmethylene)bis(5,5dimethylcyclohexane-1,3-dione); nano silica chloride

\section{INTRODUCTION}

Knoevenagel condensation is one of the elemental reactions in organic chemistry. Treatment of aromatic aldehydes with 5,5-dimethyl-1,3-cyclohexanedione (1) under the same reaction conditions Knoevenagel condensation and Michael addition have taken place 2,2'-(arylmethylene)bis(5,5-dimethylcyclohexane-1,3-dione) (3) are obtained in good yield. 2,2 -(arylmethylene)bis(5,5dimethylcyclohexane-1,3-dione) derivatives are important substances for synthesis of xanthenes that display biological and therapeutic role such as antibacterial and antiviral activities ${ }^{1}$ and also are used in laser technology. ${ }^{2}$ There are several methods reported for the synthesis of 2,2' -(arylmethylene)bis(5,5-dimethylcyclohexane1,3-dione). ${ }^{3-6}$ These reactions have been reported at catalyzed conditions for example $\mathrm{SDS}^{6 \mathrm{~b}}$ molecular iodine, ${ }^{4} \mathrm{HClO}_{4}-\mathrm{SiO}_{2}$ and $\mathrm{PPA}-\mathrm{SiO}_{2}$ (Ref. 3) in water or acetonitrile at reflux condition, solvent free conditions at $50-100{ }^{\circ} \mathrm{C}$, (Ref. 5) ultrasonic ${ }^{7}$ and microwave. ${ }^{8}$ The above mentioned methods for the production of '2,2 (arylmet-hylene)bis(5,5-dimethylcyclohexane-1,3-dione), most are not general or use unconventional reagents and conditions which are not desirable for industrial purposes, however, suffer from some disadvantages involving long reaction time, harsh reaction conditions, alternative energy source like ultrasonic and microwave, unsatisfactory yields and use of organic solvents and catalysts. Therefore it was thought worthwhile to develop a new and mild methodology that overcomes the drawbacks of previous methods. But in our procedure this reaction was done with nano silica chloride in excellent yield.

The use of heterogeneous catalysts provides a perfect solution to overcome the above limitations. In recent years, the use of reagents and catalysts on solid supports has received significant attention. ${ }^{9}$ Nano Silica gel is one of the extensively used surface material supports for different chemical transformations in organic chemistry. One such modified nano silica is nano silica chloride (nano $\mathrm{SiO}_{2}-\mathrm{Cl}$ ) that at the first time we reported to be an efficient catalyst for the synthesis of many organic compounds such as the amorphous silica chloride.

We wish to report an efficient method for one pot Knoevenagel condensation and Michael addition of dimedone with aromatic aldehydes catalyzed by nano silica chloride (nano $\mathrm{SiO}_{2}-\mathrm{Cl}$ ) as a simple and highly effective heterogeneous catalyst. Nano Silica gel was surface-modified by using thionyl chloride according to a know procedure, which acts as a mild and efficient catalyst, can be a useful and cheap catalyst for the synthesis of 2,2 -(arylmethylene)bis(5,5-dimethylcyclohexane-1,3-dione). Our studies have shown that thionyl chloride is a satisfactory chlorinating agent for silica, if used undiluted. The extent of reaction with thionyl chloride gives values for active silanols per unit area of silica surface, comparable to other method, for deter-

* Author to whom correspondence should be addressed. (E-mail: farideh_piri@yahoo.com) 
mining available activities. Nano silica chloride was prepared by the readily available material and can also be easily removed from the reaction mixture.

\section{EXPERIMENTAL SECTION}

\section{Preparation of Nano Silica Chloride}

To an oven-dried $\left(120^{\circ} \mathrm{C}\right)$ Silica gel nanoparticle (average size $\approx 20 \mathrm{~nm})(5 \mathrm{~g})$ in a round bottomed flask $(250 \mathrm{~mL})$ equipped with a condenser and a drying tube, was added thionyl chloride $(100 \mathrm{~mL})$ and refluxed for one week. The excess thionyl chloride was distilled off. The resulting white-grayish powder was flame-dried and stored in a tightly capped bottle.

\section{Typical Experimental Procedure}

To a mixture of dimedone $(2 \mathrm{mmol})$ and aromatic aldehyde $(1 \mathrm{mmol})$ in $\mathrm{CH}_{2} \mathrm{Cl}_{2}(5 \mathrm{~mL})$ was added nano silica chloride $(10 \mathrm{mg})$ at $40{ }^{\circ} \mathrm{C}$. The mixture was stirred for a specified period (Table 1). The progress of the reaction was monitored by TLC. After complete conversion of the starting material, as indicated by TLC, the reaction mixture was diluted with warm methylenedichloride $(25 \mathrm{~mL})$ filtered and concentrated under reduced pressure to obtain the crude solid, the crude solid was purified by recrystallization from $99 \% \mathrm{EtOH}$ to give 2,2 -(arylmethylene)bis(5,5-dimethylcyclohexane1,3-dione) derivatives (Entry $\mathrm{a}-\mathrm{m})$. Product were characterized according to their data of ${ }^{1} \mathrm{H}$ NMR and ${ }^{13} \mathrm{C}$ NMR, mass spectra and melting point.

The representative spectral $\left({ }^{1} \mathrm{H}\right.$ NMR and ${ }^{13} \mathrm{C}$ NMR) data 2,2 -(arylmethylene)bis(5,5-dimethylcyclohexane-1,3-dione) derivatives $3 \mathrm{a}-\mathrm{m}$ are given below.

Compound 3a: ${ }^{1} \mathrm{H}$ NMR (250 MHz, DMSO-d 6 ): 0.98 $(\mathrm{s}, 6 \mathrm{H}), 1.10(\mathrm{~s}, 6 \mathrm{H}), 2.28-2.50(\mathrm{~m}, 8 \mathrm{H}), 6.07(\mathrm{~s}, 1 \mathrm{H})$, 6.96, 7.39 (m, 5H), 8.78 (brs, 2H). ${ }^{13} \mathrm{C}$ NMR (63 MHz, DMSO-d $\mathrm{d}_{6}$ : $18.42,21.65,31.43,32.57,46.01,47.44$, $115.00,119.86,123.10,124.29,127.58,182.22,195.33$.

Compound 3b: ${ }^{1} \mathrm{H}$ NMR (250 MHz, DMSO-d $\left.{ }_{6}\right): 1.00$ (s, 6H), $1.18(\mathrm{~s}, 6 \mathrm{H}), 2.31-2.51(\mathrm{~m}, 8 \mathrm{H}), 6.18(\mathrm{~s}, 1 \mathrm{H})$, 7.01-7.41 (m, 4H), 9.12 (brs, 2H). ${ }^{13} \mathrm{C}$ NMR (63 MHz, DMSO-d $)_{6}$ : 27.42, 29.60, 31.43, 32.47, 46.42, 47.04, $115.26,117.12,117.21119 .65,121.60,125.29,129.28$, 189.41, 190.65 .

Compound 3c: ${ }^{1} \mathrm{H}$ NMR (250 MHz, DMSO-d 6 ): 0.99 (s, 6H), $1.08(\mathrm{~s}, 6 \mathrm{H}), 2.33-2.48(\mathrm{~m}, 8 \mathrm{H}), 3.51(\mathrm{~s}, 3 \mathrm{H})$, 6.09 (s, 1H), 7.39 (m, 4H), 9.51 (brs, 2H). ${ }^{13} \mathrm{C} \mathrm{NMR} \mathrm{(63}$ MHz, DMSO-d $\mathrm{d}_{6}$ ): 22.42, 27.61, 31.41, 32.41, 48.48, $49.04,74.02,113.26,122.15,128.69,130.30,135.22$, 184.01, 189.63.

Compound 3d: ${ }^{1} \mathrm{H}$ NMR (250 MHz, DMSO-d $\left.{ }_{6}\right): 1.11$ (s, 6H), $1.18(\mathrm{~s}, 6 \mathrm{H}), 2.40-2.57(\mathrm{~m}, 8 \mathrm{H}), 6.00(\mathrm{~s}, 1 \mathrm{H})$, 7.21-7.38 (m, 4H), 10.02 (brs, 2H). ${ }^{13} \mathrm{C}$ NMR (63 MHz,
DMSO-d $)_{6}: 27.42,29.60,31.43,32.47,46.42,47.04$, 115.26, 119.65, 121.60, 125.29, 145.28, 189.41, 190.65 .

Compound 3e: ${ }^{1} \mathrm{H}$ NMR $\left(250 \mathrm{MHz}, \mathrm{DMSO}-\mathrm{d}_{6}\right): 0.97$ $(\mathrm{s}, 6 \mathrm{H}), 1.05(\mathrm{~s}, 6 \mathrm{H}), 2.11-2.50(\mathrm{~m}, 8 \mathrm{H}), 6.11(\mathrm{~s}, 1 \mathrm{H})$, 7.39-7.88 (m, 4H), 11.12 (brs, 2H). ${ }^{13} \mathrm{C}$ NMR (63 MHz, DMSO-d $)_{6}$ : 18.90, 28.17, 30.94, 32.47, 46.42, 47.35, 115.26, 119.65, 121.14, 121.49, 141.58, 189.41, 191.88 .

Compound 3f: ${ }^{1} \mathrm{H}$ NMR (250 MHz, DMSO- $\left.\mathrm{d}_{6}\right): 1.11$ (s, 6H), $1.12(\mathrm{~s}, 6 \mathrm{H}), 2.18-2.27(\mathrm{~m}, 8 \mathrm{H}), 6.18(\mathrm{~s}, 1 \mathrm{H})$, 7.01 (d, 2H), 7.39 (d, 2H), 11.58 (brs, 2H). ${ }^{13} \mathrm{C}$ NMR (63 MHz, DMSO-d 6 ): 27.45, 29.25, 32.43, 33.47, 46.82, 47.44, 119.36, 118.65, 138.60, 131.29, 148.28, 190.41, 198.65 .

Compound 3g: ${ }^{1} \mathrm{H}$ NMR (250 MHz, DMSO-d $\left.\mathrm{d}_{6}\right): 1.11$ $(\mathrm{s}, 6 \mathrm{H}), 1.14(\mathrm{~s}, 6 \mathrm{H}), 2.17-2.59(\mathrm{~m}, 8 \mathrm{H}), 6.08(\mathrm{~s}, 1 \mathrm{H})$, $6.71(\mathrm{~d}, 2 \mathrm{H}), 7.35$ (d, 2H), 10.58 (brs, $2 \mathrm{H}) .{ }^{13} \mathrm{C} \mathrm{NMR}$ (63 MHz, DMSO-d ${ }_{6}$ ): 18.44, 20.68, 31.35, 32.47, 46.42, 47.04, 113.16, 115.22, 116.60, 120.05, 133.29, 159.28, $171.51,185.41,190.85$.

Compound 3h: ${ }^{1} \mathrm{H}$ NMR (250 MHz, DMSO-d 6 ): 1.01 $(\mathrm{s}, 6 \mathrm{H}), 1.14(\mathrm{~s}, 6 \mathrm{H}), 2.19-2.57(\mathrm{~m}, 8 \mathrm{H}), 6.02(\mathrm{~s}, 1 \mathrm{H})$, $6.96(\mathrm{~d}, 2 \mathrm{H}), 7.35$ (d, 2H), 11.58 (brs, $2 \mathrm{H}) .{ }^{13} \mathrm{C} \mathrm{NMR}$ (63 MHz, DMSO-d ${ }_{6}$ ): 17.14, 21.68, 31.35, 32.47, 46.42, 47.04, 113.16, 121.65, 128.60, 135.29, 139.28, 189.41, 192.85 .

Compound 3i: ${ }^{1} \mathrm{H}$ NMR (250 MHz, DMSO-d $\left.\mathrm{d}_{6}\right): 1.01$ $(\mathrm{s}, 6 \mathrm{H}), 1.12(\mathrm{~s}, 6 \mathrm{H}), 2.25-2.51(\mathrm{~m}, 8 \mathrm{H}), 6.21(\mathrm{~s}, 1 \mathrm{H})$, $6.96(\mathrm{~d}, 2 \mathrm{H}), 7.35$ (d, 2H), 11.58 (brs, 2H). ${ }^{13} \mathrm{C}$ NMR (63 MHz, DMSO-d ${ }_{6}$ ): 19.42, 22.60, 30.51, 32.53, 45.25, 46.24, 113.26, 121.65, 128.60, 135.29, 139.80, 189.41, 192.65 .

Compound 3j: ${ }^{1} \mathrm{H}$ NMR (250 MHz, DMSO-d $\left.{ }_{6}\right): 0.99$ $(\mathrm{s}, 6 \mathrm{H}), 1.01(\mathrm{~s}, 6 \mathrm{H}), 2.23-2.51(\mathrm{~m}, 8 \mathrm{H}), 2.35(\mathrm{~s}, 3 \mathrm{H})$, 6.15 (s, 1H), 7.12 (d, 2H), 7.39 (d, 2H), 11.58 (brs, 2H). ${ }^{13} \mathrm{C}$ NMR (63 MHz, DMSO-d $\mathrm{d}_{6}$ ): 27.42, 23.20, 31.43, 32.47 , 44.12, 46.42, 47.04, 119.21, 119.65, 128.60, 131.29, 137.28, 185.24, 192.22 .

Compound 3k: ${ }^{1} \mathrm{H}$ NMR (250 MHz, DMSO-d $\left.\mathrm{d}_{6}\right): 1.12$ $(\mathrm{s}, 6 \mathrm{H}), 1.18(\mathrm{~s}, 6 \mathrm{H}), 2.28-2.50(\mathrm{~m}, 8 \mathrm{H}), 2.33(\mathrm{~s}, 6 \mathrm{H})$, 5.96 (s, 1H), 6.96 (d, 2H), 7.39 (d, 2H), 10.38 (brs, 2H).

${ }^{13} \mathrm{C}$ NMR (63 MHz, DMSO-d $\mathrm{d}_{6}$ ): 25.32, 27.21, 31.31, $31.57,46.36,47.84,52.31,119.56,121.21,127.89$, $132.31,137.31,189.45,192.33$.

Compound 31: ${ }^{1} \mathrm{H}$ NMR (250 MHz, DMSO-d $\left.\mathrm{d}_{6}\right): 1.10$ $(\mathrm{s}, 6 \mathrm{H}), 1.25(\mathrm{~s}, 6 \mathrm{H}), 2.29-2.45(\mathrm{~m}, 8 \mathrm{H}), 3.51(\mathrm{~s}, 3 \mathrm{H})$, 5.86 (s, 1H), 6.99 (d, 2H), 7.39 (d, 2H), 11.58 (brs, 2H). ${ }^{13} \mathrm{C}$ NMR (63 MHz, DMSO-d $\mathrm{d}_{6}$ ): 25.52, 29.22, 31.31, $32.57,46.49,47.24,74.14,113.16,118.62,125.62$, 127.20, 132.28, 190.41, 192.65 .

Compound 3m: ${ }^{1} \mathrm{H}$ NMR (250 MHz, DMSO- $\mathrm{d}_{6}$ ): $1.11(\mathrm{~s}, 6 \mathrm{H}), 1.22(\mathrm{~s}, 6 \mathrm{H}), 2.28-2.50(\mathrm{~m}, 8 \mathrm{H}), 3.46(\mathrm{~s}$, $3 \mathrm{H}), 3.59(\mathrm{~s}, 3 \mathrm{H}), 5.85(\mathrm{~s}, 1 \mathrm{H}), 6.96-\mathrm{r} 7.39(\mathrm{~m}, 3 \mathrm{H})$, 10.18 (brs, $2 \mathrm{H}) .{ }^{13} \mathrm{C}$ NMR (63 MHz, DMSO-d 6 ): 27.42, 29.60, 31.43, 32.47, 46.42, 47.04, 73.5, 74, 116.26, $119.65,128.60,131.29,137.28,189.11,190.22$. 
Table 1. Comparison of results for the synthesis of 2,2'-(4-nitrophenylmethylene)bis(5,5-dimethylcyclohexane-1,3-dione) catalyzed by some of the silicon catalysts at the same conditions

\begin{tabular}{cccc}
\hline Entry & Catalyst & Time $/ \mathrm{h}$ & Yield $/ \%$ \\
\hline 1 & Amorphous $\mathrm{SiO}_{2}$ & 24 & 71 \\
2 & Nano $\mathrm{SiO}_{2}$ & 6.25 & 97 \\
3 & Amorphous $\mathrm{SiO}_{2}-\mathrm{Cl}$ & 3 & 95 \\
4 & ${\text { Nano } \mathrm{SiO}_{2}-\mathrm{Cl}}$ & 1.10 & 98 \\
\hline
\end{tabular}

\section{RESULTS AND DISCUSSION}

In this paper, a much more simple and effective catalytic route for the synthesis of '2,2 -(arylmethylene)bis(5,5dimethylcyclohexane-1,3-dione) under aerobic conditions is described. $10 \mathrm{mg}$ of amorphous silicon dioxide, nano silicon dioxide, amorphous silica chloride and nano silica chloride, catalyzed synthesis of '2,2 -(arylmethylene)bis(5,5-dimethylcyclohexane-1,3-dione). In order to show the applicability and efficiency of this method, our results have been compared with some of the same catalysts on the synthesis of 2,2-(arylmethylene)bis(5,5-dimethylcyclohexane-1,3-dione). As you can see in Table 1, nano silica chloride is superior to the other catalysts.

The reaction of dimedone with an aromatic aldehyde in the presence of nano silica chloride as catalyst, leads to the formation of the corresponding' 2,2 -(arylmethylene)bis(5,5-dimethylcyclohexane-1,3-dione) (3) (Scheme 1).

We investigated the Knoevenagel condensation products of 5,5-dimethyl-1,3-cyclohexanedione (dimedone) with aromatic aldehydes, but we was obtained Michael addition product. Thus it is elucidated that dimedone is not a Knoevenagel reagent but it reacts further to electron poor alkenes. Benzylidene which is formed by nucleophilic addition of dimedone to the aromatic aldehyde followed by dehydration, in the Michael addition type to give 2,2'-(arylmethylene)bis(5,5-dimethylcyclohexane-1,3-dione) 3 (Scheme 1). We found that condensation of dimedone and aromatic aldehydes gave only 2,2'-(arylmethylene)bis(5,5-dimethylcyclohexane1,3-dione) $\mathbf{3}$ as single product, even in 1:1 (aldehyde:dimedone) experiments. Xanthene as a cyclized product was not obtained. The results of our detailed investigations into this reaction are presented here and report, a very simple and highly efficient method for the synthesis of 2,2'-(arylmethylene)bis(5,5-dimethylcyclohexane-1,3-dione) 3 by condensation between dimedone and various aromatic aldehydes in $\mathrm{CH}_{2} \mathrm{Cl}_{2}$ at $40{ }^{\circ} \mathrm{C}$ with stirring (Scheme 1). When all the reactions were completed giving excellent yields of the product 3 .

The effect of electron and the nature of substituents on the aromatic ring did not show strongly obvious effects in terms of yields under the reaction condition. Benzaldehyde and other aromatic aldehydes containing electron withdrawing groups (such as nitro group, halide) or electron-donating groups (such as $N, N$-dimethyle amino group, methoxy group) were employed and reacted well to give the corresponding 2,2'-(arylmethylene)bis(5,5dimethylcyclohexane-1,3-dione) derivatives in good to

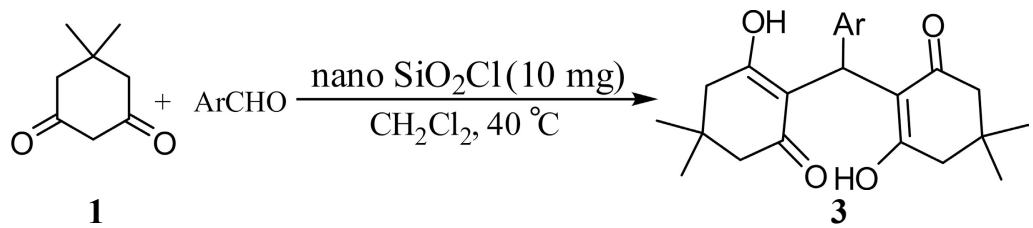

Scheme 1. Nano silica chloride catalyzed synthesis of 2,2'-(arylmethylene)bis(5,5-dimethylcyclohexane-1,3-dione).

Table 2. Silica chloride catalyzed synthesis of 2,2'-(arylmethylene)bis(5,5-dimethylcyclohexane-1,3-dione)

\begin{tabular}{|c|c|c|c|c|}
\hline Entry & $\mathrm{ArCHO}$ & Time $/ \mathrm{h}$ & Yield $^{\mathrm{a}, \mathrm{b}} / \%$ & m.p. \\
\hline $\mathrm{a}$ & $\mathrm{PhCHO}$ & 1.35 & 83 & $190-192$ \\
\hline $\mathrm{b}$ & 2-Cl PhCHO & 2.45 & 70 & $197-199$ \\
\hline $\mathrm{c}$ & 2-MeO PhCHO & 2.50 & 92 & $120-125$ \\
\hline d & $2-\mathrm{NO}_{2} \mathrm{PhCHO}$ & 1.00 & 92 & $182-184$ \\
\hline e & $3-\mathrm{NO}_{2} \mathrm{PhCHO}$ & 1.10 & 97 & $125-127$ \\
\hline $\mathrm{f}$ & $4-\mathrm{NO}_{2} \mathrm{PhCHO}$ & 1.00 & 97 & $190-192$ \\
\hline g & 4-F PhCHO & 2.00 & 96 & $190-192$ \\
\hline $\mathrm{h}$ & 4-Cl PhCHO & 2.00 & 96 & $146-148$ \\
\hline $\mathrm{i}$ & 4-Br $\mathrm{PhCHO}$ & 1.50 & 98 & $161-163$ \\
\hline $\mathrm{j}$ & 4-Me PhCHO & 2.00 & 83 & $132-134$ \\
\hline $\mathrm{k}$ & 4- $\mathrm{NMe}_{2} \mathrm{PhCHO}$ & 1.00 & 88 & $186-188$ \\
\hline 1 & 4-MeO $\mathrm{PhCHO}$ & 3.50 & 95 & $140-142$ \\
\hline $\mathrm{m}$ & 3,4-di $\mathrm{MeO} \mathrm{PhCHO}$ & 4.20 & 92 & $186-189$ \\
\hline
\end{tabular}

(a) Yields refer to crude product (isolated product).

(b) All products were identified by comparison of their physical and spectral data with those of authentic samples. 

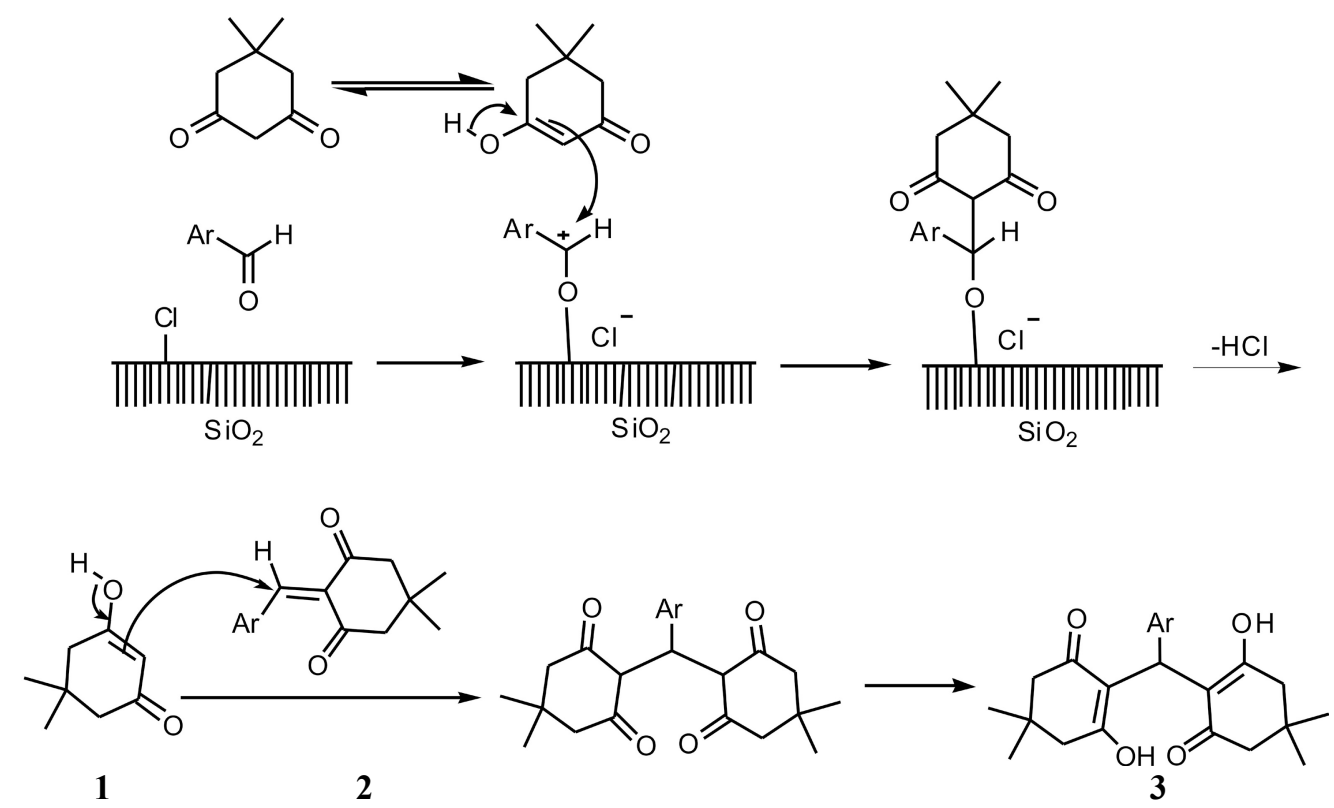

Scheme 2. Mechanism of synthesis 2,2'-(arylmethylene)bis(5,5-dimethylcyclohexane-1,3-dione).

excellent yields.

The formation of compound $\mathbf{3}$ can be explained by the mechanism that presented in Scheme 2. The reaction sequence is one-pot Knoevenagel condensation, Michael addition and tautomerization. Dimedone adds easily to electron-poor alkenes in the Michael addition fashion. Thus, cascade reactions ${ }^{10}$ of addition, elimination and addition could be achieved, but the intermediate alkenes 2 were not available even in 1:1 experiments according to the present reaction conditions. ${ }^{11}$ The electron-poor alkenes $\mathbf{2}$ are useful intermediates for Michael additions.

These are frequently performed in solution under base catalysis, ${ }^{12}$ but even solvent free versions at base, ${ }^{13}$ acid, ${ }^{14}$ or Lewis acid, ${ }^{15}$ catalysis were never quantitative and required chromatographic purification techniques. This poor situation did not change when dry solid supports and microwave heating were applied.

Inspection of the SEM and TEM images of a sample catalyst from this reaction indicates the involvement of silica chloride nanoparticles with a size distribution of 15-35 nm (average $20 \mathrm{~nm}$ ), (Fig s. 1 and 2). A number of different solvents such as THF, $\mathrm{Et}_{2} \mathrm{O}$, nhexane, toluene, $\mathrm{CH}_{3} \mathrm{CN}$ and $\mathrm{CH}_{2} \mathrm{Cl}_{2}$ were also investigated and it turned out that $\mathrm{CH}_{2} \mathrm{Cl}_{2}$ was better suited as solvent for this purpose. The work up of the reaction was performed using simple centrifuged, filtration and the recovered nano silica chloride was readily used in 7 subsequent reactions and exhibited consistent catalytic activity for the synthesis of 2,2' -(arylmethylene)bis(5,5dimethylcyclohexane-1,3-dione) with out further purification. However, owing to extensive agglomeration, the activity of the catalyst dramatically decreased after the seven run.

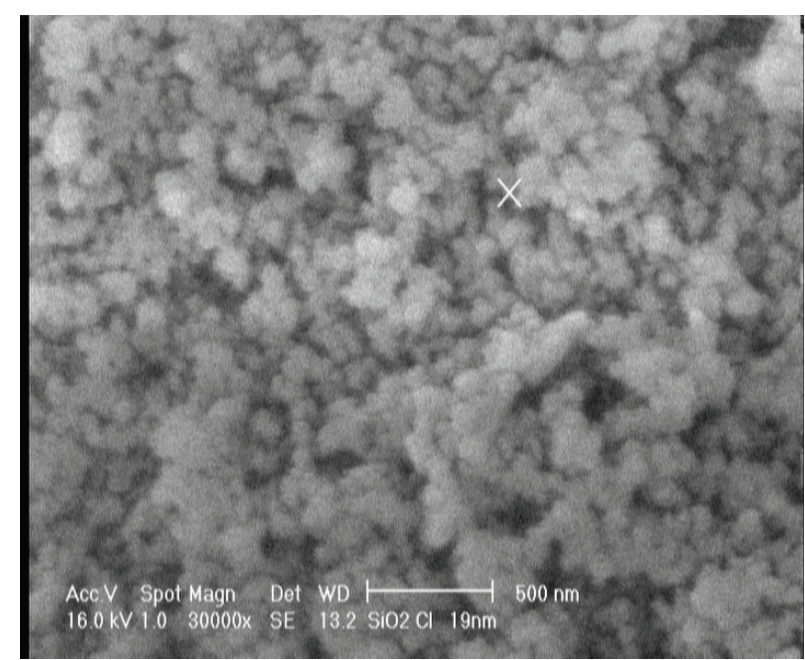

Figure 1. SEM image of silica chloride nano particle.

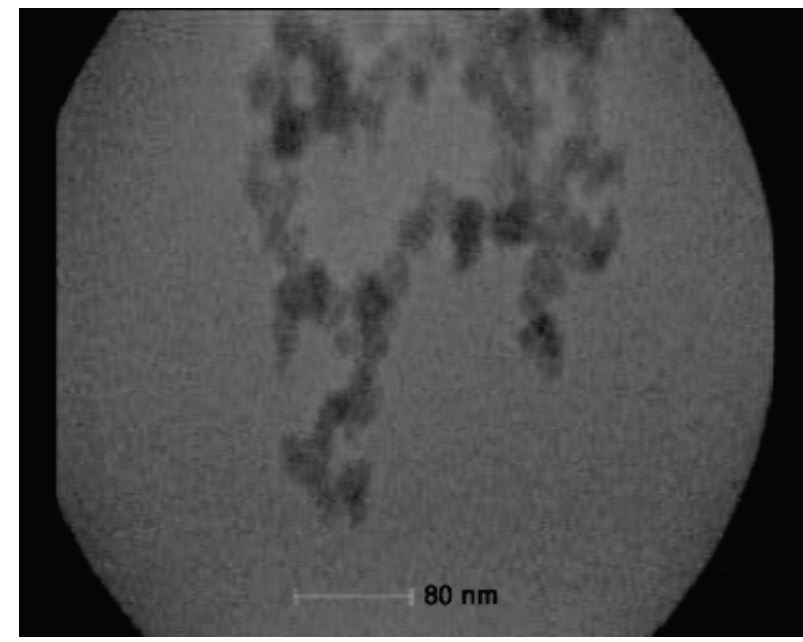

Figure 2. TEM image of silica chloride nano particle. 


\section{CONCLUSION}

In conclusion, a mild, efficient and simple method for the one pot synthesis 2,2'-(arylmethylene)bis(5,5dimethylcyclohexane-1,3-dione) derivatives has been described using nano silica chloride as a heterogeneous catalyst. The main advantage of this method is that it requires mild reaction conditions with operational simplicity and with excellent yields.

Acknowledgements. We are grateful to Institute for Advanced Studies in Basic Sciences (IASBS) and Imam Hossein University for financial support of this work.

\section{REFERENCES}

1. R. M. Ion, and D. Frackowiak, Acta Biochim. Pol. 45 (1998) 833.

2. (a) O. Sirkecioglu, N. Talinli, and A. Akar, J. Chem. Res. (1995) 502. (b) S. C. Bergmeier, Tetrahedron. 56 (2000) 2561.

3. S. Kantevari, R. Bantu, and L. Nagarapu, J. Mol. Catal. 53 (2007) 269.

4. M. Kidwai, and V. Bansal, J. Mol. Catal. 76 (2007) 268.

5. G. Kaupp, M. R. Naimi-Jarnal, and J. Schmeyers, Tetrahedron. 59 (2003) 3753.
6. (a) D. Shi, Y. Wang, Z. Lu,and G. Dai, Synth. Commun. 30 (2000) 713. (b) L. B. Liu, T. S. Jin, L. S. Han, and T. S. Qina, J. Chem. (2006) 117.

7. G. Cravotto, G. M. Nano, G. Palmisano, and S. Tagliapietra, Synthesis. (2003) 1286.

8. (a) G. Kaupp, and M. R. Naimi-Jamal, Chem. Eur. J. 8 (2002) 594. (b) G. Kaupp, J. Schmeyers, and J. Boy, J. Prakt. Chem. 342 (2000) 269.

9. (a) A. McKillop, and D. W. Young, Synthesis. (1979) 401. (b) A. Cornelis, and P. Laszlo, Synthesis. (1985) 909. (c) M. Ali Hashmat, and M. McDermott, Tetrahedron Lett. 43 (2002) 6271.

10. (a) Y. Kamitori, M. Hojo, R. Masuda, T. Kimura, and T. Yoshida, J. Org. Chem. 51 (1986) 1427. (b) H. Firouzabadi, N. Iranpoor, H. Hazarkhani, and B. Karimi, J. Org. Chem. 67 (2002) 2572. (c) M. Sathe, A. K. Gupta, and M. P. Kaushik, Tetrahedron Lett. 47 (2006) 3107.

11. (a) G. Kaupp,and M. R. Naimi-Jamal, Chem. Eur. J. 8 (2002) 594. (b) G. Kaupp, J. Schmeyers, and J. Boy, J. Prakt. Chem. 342 (2000) 269.

12. (a) H. R. Shaterian, M. Ghashang, and A. Hassankhani, Dyes Pigment. 76 (2008) 564. (b) G. Kaupp, M. R. Naimi-Jamal, and J. Schmeyer, Tetrahedron. 59 (2003) 3753.

13. M. A. A. Aziz, H. A. Daboun, and S. M. Gawad, J. Prakt. Chem 332 (1990) 610.

14. G. W. V. Cave, and C. L. Raston, Chem. Commun. (2000) 2199

15. H. Kotsuki, K. Arimura, T. Ohishi, and R. Maruzasa, J. Org. Chem. 641 (1999) 3770 